\title{
OUVIDORIA DO SUS COMO INSTRUMENTO DA DEMOCRACIA PARTICIPATIVA: O CASO DE ANGRA DOS REIS
}

\author{
Maria Cláudia Nicoláu Capaz' \\ Vanessa de Almeida Guimarães ${ }^{2}$
}

\begin{abstract}
Resumo
Como a participação cidadã é um direito garantido no texto constitucional e uma das principais diretrizes do Sistema Único de Saúde - SUS, criado pela Lei $n^{\circ} 8.080 / 90$, a Lei $n^{\circ} 8.142 / 90$ (cria o Conselho de Saúde e a Conferência de Saúde) a inseriu na gestão, no controle e na fiscalização dos serviços de saúde. Dessa forma, deseja-se analisar se (e como) a implantação da Ouvidoria na Secretaria Municipal de Saúde de Angra dos Reis proporcionou e ampliou ao cidadão o acesso ao seu direito de participação na gestão da saúde do município. A pesquisa se baseou em análise documental dos dados registrados em períodos distintos, antes e depois da implantação da Ouvidoria. Após avaliação, concluiu-se que a Ouvidoria do SUS desse município atinge sua finalidade institucional na gestão pública de saúde.
\end{abstract}

Palavras-Chave: Ouvidoria. Participação cidadã. Controle social.

1 Especialista em Gestão da Administração Pública pela Universidade Federal Fluminense e Especialista em Regulação em Saúde no SUS pelo Instituto Sírio-Libanês de Ensino e Pesquisa. Diretora do Departamento de Ouvidoria do SUS da Secretaria Municipal de Saúde de Angra dos Reis desde janeiro de 2017. (mariaccapaz@uol.com.br) (www.angra.rj.gov.br) (ssa.dosus@angra.rj.gov.br)

2 Mestra em Administração pela Universidade Federal Fluminense - UFF, Docente no Centro Federal de Educação Tecnológica Celso Suckow da Fonseca - CEFET/RJ. (vanessaguim@hotmail.com) 


\begin{abstract}
Being citizen participation a guaranteed right in the constitutional text and one of the main guidelines of the Unified Health System - hereby SUS, created by Law n. 8.080/90, the Law n. 8.142/90 (creates the Health Council and the Health Conference) has inserted it in the management, control and inspection of health services. Thus, there's a wish to analyze whether (and how) the implementation of an Ombudsman at the Municipal Health Department of Angra dos Reis has provided and extended to citizens access to their right to participate in the health management of the county. The research was based on documentary analysis of the data registered in different periods, before and after Ombudsman's implementation. After evaluation, it was concluded that the Ombudsman's Office of the SUS of this county fully reaches its institutional purpose in public health management.
\end{abstract}

Keywords: Ombudsman. Citizen participation. Social control. 


\section{INTRODUÇÃO}

A Constituição Federal de 1988, no artigo 196, explicita que a "saúde é direito de todos e dever do Estado garantido mediante políticas sociais e econômicas que visem à redução do risco da doença e de outros agravos e ao acesso universal e igualitário às ações e aos serviços para sua promoção, proteção e recuperação" (BRASIL, 1988).

Dessa forma, a criação do Sistema Único de Saúde - SUS, regulamentado pelas Leis Orgânicas da Saúde $n^{\circ}$ 8.080/90 e n 8.142/90, propiciou a maior política de inclusão social e importante ponto de mudança e evolução institucional no Brasil. Além disso, gerou entendimento amplo sobre o direito à saúde e o papel do Estado na garantia desse direito.

Ainda mais, a Lei n 8.142/90 introduziu a participação popular na gestão, no controle e fiscalização dos serviços de saúde. De acordo com SOUZA et al. (2007, p. 27), podemos colocar que a participação é "a alma do SUS na promoção da saúde", pois a construção da cidadania passa, fundamentalmente, pela participação.

Assim, as Ouvidorias do SUS foram criadas como instrumentos de viabilização dos princípios que dispõem a Constituição Federal e a Legislação do SUS, como porta de acesso para que o cidadão exerça seus direitos e para o fortalecimento do controle social. Para tanto, leva-se em conta que, como canal de escuta qualificada, a Ouvidoria contribui de forma a garantir o exercício da cidadania e consolida a democracia participativa.

Nesse sentido, destaca-se que, em 26 de junho de 2017, foi promulgada a Lei $\mathrm{n}^{\circ}$ 13.460/17, que dispõe sobre a participação, proteção e defesa dos direitos do usuário dos serviços públicos da administração pública (incluindo, aqui, o SUS). Ressalta-se que, em seu capítulo IV, ela versa especificamente sobre as Ouvidorias; enquanto o capítulo $\vee$ aborda os conselhos de usuários. Dessa maneira, embora seja genérica, tal lei corrobora a Lei 8.142/90 mencionada nos parágrafos anteriores e reconhece a Ouvidoria como instrumento de participação popular.

Diante do exposto, tem-se o seguinte problema de pesquisa: como a implantação da Ouvidoria do SUS em uma Secretaria Municipal de Saúde - SMS, de um município de médio porte, pode proporcionar ao cidadão, usuário dos serviços públicos de saúde, o acesso ao processo da democracia participativa?

Dessa forma, o presente trabalho tem como objetivo principal analisar se e como a implantação da Ouvidoria do SUS da SMS de Angra dos Reis proporcionou ao cidadão o acesso a seu direito de participação no processo democrático. Tem-se como objetivos específicos: (1) verificar a dinâmica de acesso do cidadão antes e depois da implantação da Ouvidoria do SUS nesse município; (2) identificar e quantificar os fatores que motivaram o cidadão a se manifestar por meio da Ouvidoria do SUS; e (3) apresentar o quantitativo de manifestações dos cidadãos que acessaram a Ouvidoria do SUS.

Para tanto, foram verificados os dados, extraídos das manifestações dos cidadãos inseridas no Sistema Informatizado OuvidorSUS, em três períodos distintos da Ouvidoria do SUS: antes (2009-2011), durante (2012-2014) e após a implantação (2016-2018).

A relevância deste trabalho reside na percepção de que o cidadão, ao se manifestar pela Ouvidoria do SUS, pode orientar as ações da gestão da saúde pública por resultados, atuando como 
instrumento da democracia participativa. Assim, esse artigo traz, além desta introdução: (2) referencial teórico, (3) procedimentos metodológicos, (4) desenvolvimento, (5) conclusões, (6) referências.

\section{REFERENCIAL TEÓRICO}

A Constituição Federal de 1988, as Leis n 8.080/90 e n 8.142/90 e a Lei n 13.460/17 (Lei de Defesa do Usuário) formam a base legal que resguarda ao cidadão o direito de exercer um papel mais ativo na formulação, no controle e na fiscalização da Política de Saúde no País. Dessa forma, o SUS consolida o usuário do sistema como cidadão de direitos, que busca serviços de saúde cujo resultado advém da sua participação.

A partir de 1988, o conceito de saúde foi ampliado para o "Estado de Bem-Estar Social", fazendo com que a Constituição fosse conhecida como "Constituição Cidadã" (SIRAQUE, 2005). As diretrizes de descentralização, atendimento integral e participação da comunidade definidas em seu artigo 198 determinam que as ações de saúde devem integrar uma rede regionalizada e hierarquizada (BRASIL, 1988).

Assim, a participação da comunidade nas ações e nos serviços públicos (contratados ou conveniados) que integram o SUS na gestão e transferências de recursos financeiros está prevista na Lei $n^{\circ} 8.142 / 90$, conforme os princípios da universalidade, equidade, integralidade e seus dispositivos. Dentro desse contexto, o sistema de saúde figura como um dos princípios da Lei $n^{\circ}$ 8.080/90, que: "[...] regula, em todo o território nacional, as ações dos serviços de saúde, executados isolados ou conjuntamente, em caráter permanente ou eventual, por pessoas naturais ou jurídicas de direito público ou privado" (BRASIL, 2007, p. 10).

A partir de 2003, o Governo Federal lançou a Política Nacional de Gestão Estratégica e Participativa - Participa SUS, visando a fomentar o desenvolvimento de formas de gestão democrática das políticas públicas no âmbito do SUS. São quatro os elementos que compõem essa política: Controle Social; Monitoramento e Avaliação da Gestão; a Ouvidoria e a Auditoria (BRASIL, 2009, p. 15).

O pilar, Monitoramento e Avaliação da Gestão do SUS, busca articular os indicadores das ações e dos serviços tradicionais, assim como os indicadores das desigualdades, de determinantes de saúde, de ações intersetoriais, culturais, ambientais e de participação social. A Auditoria, por sua vez, contribui para a alocação e utilização adequada dos recursos, a fim de garantir o acesso e a qualidade da atenção à saúde oferecida aos cidadãos.

Por intermédio dos Conselhos e pelas Conferências de Saúde, o Controle Social abrange a gestão, os trabalhadores da saúde e a sociedade civil organizada nas três esferas de governo.

Complementando o elemento político da gestão participativa, surge a Ouvidoria, que busca integrar e estimular práticas que ampliem o acesso dos usuários ao processo de avaliação das ações e serviços públicos de saúde. Nesse cenário, ela se apresenta como um canal direto de comunicação dos usuários do sistema e da comunidade, para subsidiar a política de saúde, contribuindo com o controle social.

Além disso, pela Portaria n 399 de 22 de fevereiro de 2006, foi aprovado o Pacto pela Saúde e suas Diretrizes Operacionais, representando o compromisso assumido entre os gestores das três 
esferas de governo - federal, estadual e municipal - para a atenção à saúde da população. Nele, a participação e o Controle Social estão presentes nas suas três dimensões, objetivando a superação de diferentes dificuldades do sistema de saúde (BRASIL, 2006b).

A primeira dimensão do Pacto pela Saúde é o "Pacto pela Vida", que destaca a importância da participação social na promoção da saúde com vistas às políticas públicas mais favoráveis à saúde e a vida. A participação e o controle social alcançam, então, o sentido de mobilização social para garantia do direito à saúde como um direito de cidadania por meio da segunda dimensão, o "Pacto em Defesa do SUS". Ressaltando o compromisso do gestor na responsabilidade pela qualificação das ações de participação e controle social em saúde, a terceira dimensão é o "Pacto de Gestão".

No âmbito desses dispositivos, que possibilitam a participação do cidadão na gestão pública da saúde, as Ouvidorias, os Conselhos de Saúde, as Conferências e o Orçamento Participativo integram os mecanismos existentes para essa finalidade (BRASIL, 2010).

Pretendendo ampliar a participação da comunidade e com o intuito de incentivar a criação de canais de escuta qualificada dos cidadãos, consolidar o controle social e a gestão participativa, a $12^{\mathrm{a}}$ Conferência Nacional de Saúde deliberou pela definição e implementação da Política Nacional de Ouvidorias do SUS para as três esferas de governo no ano de 2003 (BRASIL, 2013).

Contudo, para FORTES (2009), foi apenas na deliberação da $13^{a}$ Conferência de Saúde (em 2007) que ficou sensível a necessidade de criar ferramentas de participação mediante fundamentação legal vigente do SUS. A partir desse instante, a implantação das Ouvidorias descentralizadas, articulada nas três esferas de governo, passa a ser uma realidade.

Nesse contexto, o Ministério da Saúde criou o Departamento de Ouvidoria-Geral do SUS - DOGES, como exemplo concreto de participação da comunidade e democratização das informações em saúde. Coube ao DOGES formular e coordenar a Política de Ouvidoria para o SUS e possibilitar a criação de diversos espaços de escuta e participação popular (Ouvidorias do SUS) nos estados e em vários municípios do país, entre eles o município de Angra dos Reis.

Como resultado, em 2019 estão implantadas 2.105 (duas mil cento e cinco) Ouvidorias do SUS municipais em um total de mais de 5.500 (cinco mil e quinhentos) municípios no território nacional. No Estado do Rio de Janeiro, dos 92 municípios, 66 (sessenta e seis) deles contam com Ouvidorias do SUS implantadas, segundo dados da Secretaria de Estado de Saúde do RJ (SES-RJ). Isso representa $67 \%$ dos municípios do estado e $40 \%$ dos municípios do País que já contam com esse tipo de mecanismo de participação (conforme informações da Coordenação da Rede de Ouvidorias do SUS do Ministério da Saúde).

\section{METODOLOGIA}

De acordo com CELLARD (2008), a análise documental favorece a observação do processo de maturação ou de evolução de indivíduos, grupos, conceitos, conhecimentos, comportamentos, mentalidades, práticas, entre outros.

Assim, este trabalho se baseou em análise documental levantando dados registrados no sistema informatizado OuvidorSUS sobre a Ouvidoria do SUS do município de Angra dos Reis, disponi- 
bilizados pela Ouvidoria-Geral do SUS do Ministério da Saúde. Foram contemplados três momentos sequenciais: de 02 de janeiro de 2009 a 31 de dezembro de 2011 (pré-implantação); de 02 de janeiro de 2012 a 31 de dezembro de 2014 (durante a implementação); e de 02 de janeiro de 2016 a 28 de dezembro de 2018 (Ouvidoria implantada).

Os relatórios inquiridos para a amostra foram coletados em corte longitudinal (se limitaram a observar os elementos amostrais). Para análise, as manifestações foram classificadas quanto à característica da demanda; a tipificação quanto ao que se refere à manifestação ou áreas da saúde. Sob o ângulo da classificação das manifestações, as demandas foram divididas em: denúncia, elogio, informação, reclamação, solicitação e sugestão.

De acordo com a tipificação da manifestação, os assuntos foram classificados em: assistência à saúde; assistência farmacêutica; assistência odontológica; estratégia de saúde da família; gestão, onde estão incluídas as demandas referentes a recursos humanos; produtos da saúde e correlatos; Programa Farmácia Popular do Brasil; SAMU; Vigilância em Saúde, entre outros. Os dados foram analisados de maneira qualitativa por meio de técnicas de estatística descritiva.

\section{DESENVOLVIMENTO}

O município de Angra dos Reis está localizado no sul do Estado do Rio de Janeiro. Com extensão territorial de $825 \mathrm{~km}^{2}$, está inserido na $9^{a}$ Região de Saúde do RJ, denominada região da Baía da Ilha Grande - BIG, composta também pelos municípios de Paraty e Mangaratiba. Segundo estimativas do IBGE (2019), a população de Angra dos Reis atingiu em 2018 um total de 200.404 habitantes, o que representa $70 \%$ da população da BIG, que totaliza 286.726 habitantes. A região reúne ainda comunidades indígenas, quilombolas e ciganas em seu território, comunidades essas consideradas vulneráveis pelo MS.

Como forma de incentivar a participação, no período que antecedeu à implantação da Ouvidoria do SUS no município de Angra dos Reis, os cidadãos que, de alguma forma, não se sentissem atendidos pelo município em suas demandas de saúde encaminhavam suas manifestações ao DOGES/ MS, pelo tridígito 136, ou à Ouvidoria-Geral da SES-RJ. Ademais, para otimizar o serviço e na busca da garantia de preservação das informações colhidas por parte desses órgãos no âmbito federal e estadual, criou-se o sistema informatizado OuvidorSUS, que possibilita às SMS a comunicação em rede, em tempo real.

O sistema informatizado OuvidorSUS contempla três níveis de acesso: (a) nível 3, quando a Ouvidoria apenas visualiza as demandas sob sua responsabilidade e deve responder à Ouvidoria-Geral do SUS/MS através de documento oficial; (b) nível 2, em que a Ouvidoria recebe a manifestação e pode responder pelo próprio sistema, mas a demanda só pode ser concluída pela Ouvidoria-Geral do SUS/MS; e (c) nível 1, em que a Ouvidoria pode não apenas receber as demandas, mas também inserir, trabalhar, concluir e fechar as manifestações.

Até a implantação da Ouvidoria do SUS, o município de Angra dos Reis estava habilitado para o nível 2 de acesso ao sistema OuvidorSUS, onde apenas recebia as manifestações e as respondia em tempo determinado pelo DOGES (à época). Para melhor compreensão do processo de encami- 
nhamento de demandas da Ouvidoria, esclarece-se que, quando as manifestações são inseridas, elas podem ser classificadas de cinco formas: denúncia, elogio, informação, reclamação, sugestão e solicitação.

Assim, após a análise dos dados referentes ao município de Angra dos Reis, no período de 2009 a 2011, que antecedeu a implantação da Ouvidoria do SUS pela SMS, verificou-se que, numericamente, era pequena a participação do cidadão pelo canal da Ouvidoria, se comparado com os dados obtidos após a implementação (Figuras 1 e 3).

\section{FIGURA 1 - Quantitativo de manifestações por classificação}

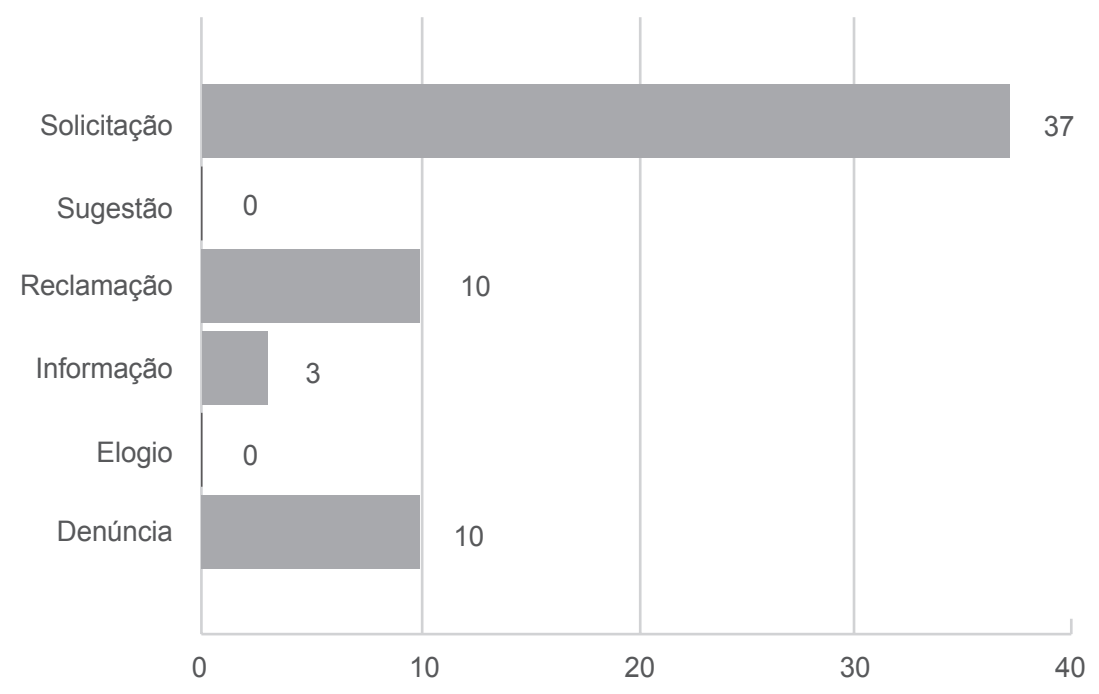

$\mathrm{N}^{\circ}$ de Manifestações

Fonte: Elaborado com base nos dados do OuvidorSUS/MS

Pela análise da Figura 1, nota-se que o quantitativo de demandas que a SMS de Angra dos Reis recebeu de 02 de janeiro de 2009 a 31 de dezembro de 2011 totalizou 60 manifestações, das quais $61 \%$ foram solicitações, $17 \%$ denúncias, $17 \%$ reclamações e $5 \%$ informações.

Nota-se, portanto, que o cidadão está priorizando suas necessidades individuais, tendo em vista o número de solicitações demandadas (37), as quais variam desde pedidos de transporte a inclusão em programas do governo federal. Não houve quaisquer registros de sugestões visando à melhoria do sistema, o que indica que, ao se manifestar, esse cidadão não está pensando numa participação democrática consciente, na busca dos seus direitos enquanto cidadão, com vistas ao coletivo, mas busca resolver seu problema imediato.

Quanto à forma de acesso do cidadão ao canal da Ouvidoria do SUS, o qual pode ser feito pessoalmente, por telefone, por correspondência (carta), por e-mail e ainda por formulário web, tem-se a Figura 2. 
FIGURA 2 - Tipo de atendimento no período de jan. 2009 a dez. 2011

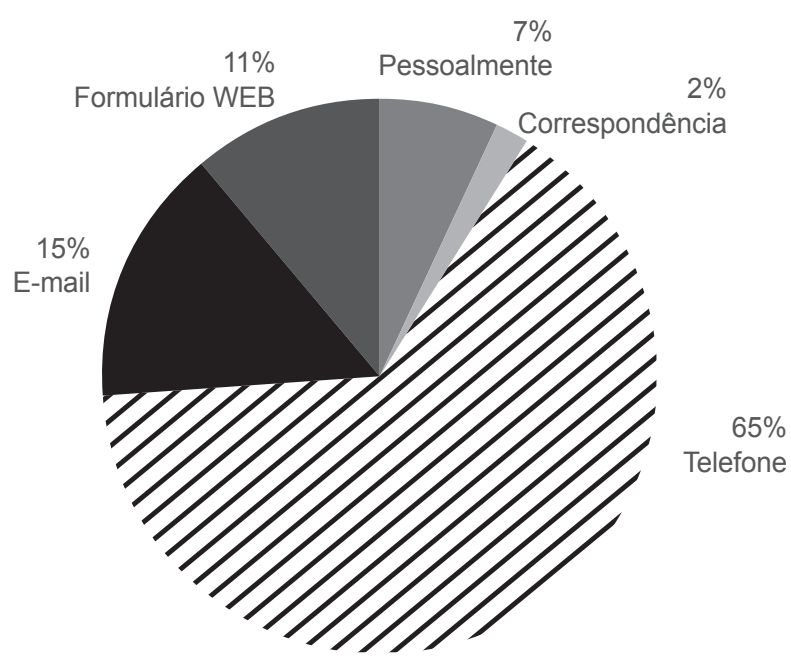

Fonte: Elaborado com base nos dados do OuvidorSUS/MS

Conforme mostra a Figura 2, das 60 manifestações do período, $65 \%$ delas foram feitas pelo telefone, seguidas de $15 \%$ por e-mail e $11 \%$ por formulário web, o que se explica pelo fato das inserções terem sido feitas pela Ouvidoria-Geral do SUS/MS ou pela SES-RJ.

Em relação à tipificação por assunto das demandas apresentadas no período em análise, tem-se a Tabela 1.

TABELA 1 - Relatório estatístico: Tipificação por Assunto X Classificação (2009-2011)

\begin{tabular}{|l|l|l|l|l|l|l|l|}
\hline Tipificação por Assunto & Denúncia & Elogio & Informação & Reclamação & Sugestão & Solicitação & Total \\
\hline Assistência à Saúde & - & - & - & - & - & 23 & $\mathbf{2 3}$ \\
\hline Assistência Farmacêutica & - & - & - & 1 & - & 9 & $\mathbf{1 0}$ \\
\hline Estratégia da Saúde da Família - ESF & 3 & - & - & - & - & - & $\mathbf{3}$ \\
\hline Gestão & 2 & - & 1 & 5 & - & 2 & $\mathbf{1 0}$ \\
\hline Produtos para saúde & - & - & - & - & - & 2 & $\mathbf{2}$ \\
\hline Programa Nacional de DST/Aids & - & - & - & - & - & 1 & $\mathbf{1}$ \\
\hline Transporte & - & - & 1 & 1 & - & - & $\mathbf{2}$ \\
\hline Vigilância em Saúde & 1 & - & 1 & 2 & - & - & $\mathbf{4}$ \\
\hline Vigilância Sanitária & 4 & - & - & 1 & - & - & $\mathbf{5}$ \\
\hline Total & $\mathbf{1 0}$ & - & $\mathbf{3}$ & $\mathbf{1 0}$ & $\mathbf{3}$ \\
\hline
\end{tabular}

Fonte: Ouvidor SUS/MS (2009, 2010, 2011) 
Nota-se que, das 60 manifestações, 37 são solicitações (61\%), das quais 23 se referem à Assistência à Saúde, quando o cidadão reivindica a marcação de exame e ou consulta que consta em fila de espera. Já em 9 (das 10 demandas), o cidadão busca Assistência Farmacêutica que trata da aquisição de medicamentos, produtos para saúde ou correlatos, fraldas, por exemplo.

Outro dado relevante da Tabela 1 é o quantitativo de 10 denúncias. Dentre elas, destacam-se três envolvendo a Estratégia de Saúde da Família - ESF, no que diz respeito às equipes incompletas nas ESF, principalmente a falta de profissional médico nas equipes; quatro voltadas à Vigilância Sanitária, que trata de estabelecimentos comerciais, supermercados, com alimentos em mau estado de conservação ou fora do prazo de validade.

Quando se trata da tipificação do assunto Gestão, o item de maior frequência foi o de reclamações com 5 registros. Elas estão direcionadas ao setor de Recursos Humanos, especialmente sobre o mau atendimento prestado por profissionais da rede pública de saúde a cidadãos. Salientam-se, também, as duas denúncias que se referiam ao uso indevido de recursos provenientes do MS para o Núcleo de Apoio à Saúde da Família (NASF).

Nesse contexto, salienta-se que, de acordo com DUARTE (2010), a participação social pode apresentar vários significados. Quando retratada politicamente, mostra-se uma inovação democrática que se relaciona aos movimentos sociais, bem como uma ação solidária em diversas dimensões sociais que busca a manutenção ou modificação da estrutura de poder.

Para DUARTE (2010), ao se manifestar em busca de uma determinada informação, o cidadão expõe a necessidade de ampliação do conceito de saúde, que pode e deve dar lugar a tudo o que conceitue, em última análise, a qualidade de vida. Ao dar sugestões, por exemplo, o cidadão contribui para a conscientização e o esclarecimento de dúvidas em relação a assuntos de relevância social e reforça a postura ativa do indivíduo quanto à saúde individual e coletiva.

Assim sendo, ao se manifestar, o cidadão exercita as reflexões críticas sobre seu papel em uma gestão participativa e efetiva a participação. Por outro lado, quando a gestão divulga suas ações, contribui para a concretização das políticas públicas. Contudo, observa-se que antes da implantação da Ouvidoria do SUS, num universo de aproximadamente 170 mil possíveis usuários do sistema de saúde, apenas 60 cidadãos se manifestaram por esse canal de escuta.

Dessa maneira, como forma de possibilitar a ampliação da participação do cidadão, seguindo os princípios constitucionais e os preceitos do SUS, o município de Angra dos Reis implantou a Ouvidoria da Secretaria de Saúde denominada Ouvidoria SUS, em outubro de 2011 (com início do atendimento ao cidadão em janeiro de 2012), pela Lei Municipal n² 2.770 de 01 de julho de 2011, em conformidade com a Resolução n 07/2011, de 13 de junho de 2011, do Conselho Municipal de Saúde.

A partir da implantação da Ouvidoria do SUS, com estrutura física, material e de recursos humanos, o município passou a atuar com o sistema OuvidorSUS/MS no nível 1, podendo, a partir de então, receber, inserir, trabalhar a manifestação e em seguida encaminhá-la ao setor da secretaria responsável pelo serviço demandado.

Constatou-se que, durante a implementação da Ouvidoria (com o serviço implantado), a participação do cidadão aumentou quantitativamente de forma considerável. No período de 02 de janeiro de 2012 a 30 de dezembro de 2014 foram acolhidas 2.112 manifestações (35,2 vezes mais que no período anterior), como mostra a Figura 3. 


\section{FIGURA 3 - Quantitativo de manifestações por classificação $(2012,2013,2014)$}

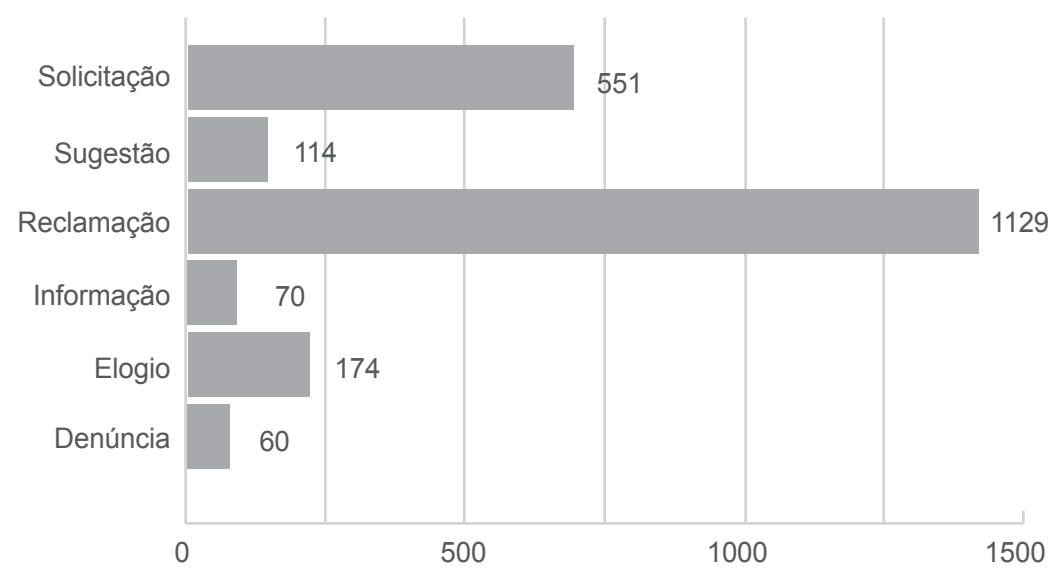

$N^{\circ}$ de Manifestações

Fonte: Elaborado com base nos dados do OuvidorSUS/MS

A implantação da Ouvidoria permitiu, portanto, aumento da participação cidadã na gestão pública, o que é relevante, uma vez que o cidadão pode apontar falhas no serviço prestado e estabelecer prioridades quanto às suas necessidades, contribuindo para a melhoria do serviço.

Nota-se que houve uma mudança na forma de manifestação do usuário durante o período de implementação da Ouvidoria (Figura 4). As formas de acesso das manifestações se deram em $35,94 \%$ dos casos por telefone; $28,46 \%$ pessoalmente; e $19,13 \%$ por formulário web (disponibilizado no portal da Prefeitura de Angra dos Reis).

FIGURA 4 - Tipo de atendimento $(2012,2013,2014)$

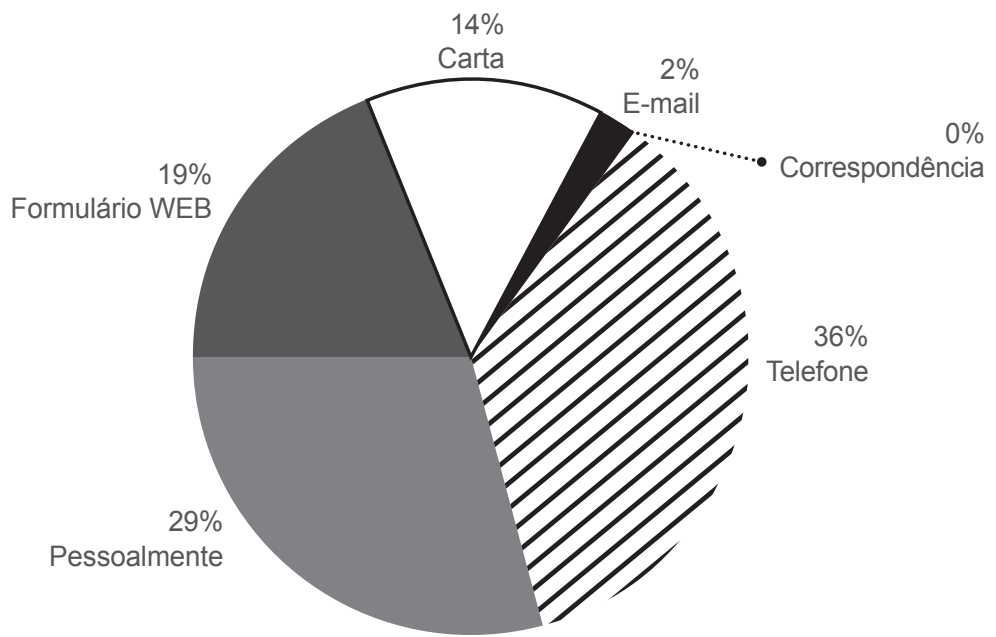

Fonte: Elaborado com base nos dados do OuvidorSUS/MS 
Em relação à tipificação por assunto, das manifestações apresentadas no período em análise, de janeiro de 2012 a dezembro de 2014, tem-se a Tabela 2.

TABELA 2 - Relatório estatístico: Tipificação X Classificação (2012 - 2014)

\begin{tabular}{|c|c|c|c|c|c|c|c|}
\hline Tipificação por Assunto & Denúncia & Elogio & Informação & Reclamação & Sugestão & Solicitação & Total \\
\hline Alimento & - & - & - & 2 & - & 2 & 4 \\
\hline Assistência à Saúde & - & - & 11 & 31 & - & 347 & 389 \\
\hline Assistência Farmacêutica & 1 & - & 1 & 12 & - & 53 & 67 \\
\hline Assistência Odontológica & - & - & - & 6 & - & 11 & 17 \\
\hline Cartão SUS & - & - & 2 & 5 & - & 3 & 10 \\
\hline Carta SUS & 2 & - & - & - & - & - & 2 \\
\hline Comunicação & - & - & - & - & - & 1 & 1 \\
\hline Estratégia de Saúde da Família - ESF & 2 & 9 & 6 & 86 & 3 & 26 & 132 \\
\hline Financeiro & - & - & - & 3 & - & 3 & 6 \\
\hline Gestão & 39 & 158 & 39 & 865 & 110 & 55 & 1266 \\
\hline Orientação em Saúde & - & - & 1 & 1 & - & - & 2 \\
\hline Ouvidoria do SUS & - & 1 & - & - & - & - & 1 \\
\hline Produtos para saúde e correlatos & - & - & 2 & 17 & - & 29 & 48 \\
\hline Programa Farmácia Popular do Brasil & - & - & - & 1 & - & - & 1 \\
\hline $\begin{array}{l}\text { Programa Nacional de Controle do } \\
\text { Tabagismo }\end{array}$ & 1 & - & - & - & - & - & 1 \\
\hline Programa Nacional de DST/Aids & - & - & - & 1 & - & - & 1 \\
\hline SAMU & 6 & 6 & 1 & 23 & - & - & 36 \\
\hline Transporte & 4 & - & 2 & 53 & 1 & 5 & 65 \\
\hline Vigilância em Saúde & 5 & - & 5 & 14 & - & 16 & 40 \\
\hline Vigilância Sanitária & - & 12 & - & 9 & - & 2 & 23 \\
\hline Total & 60 & 174 & 70 & 1129 & 114 & 551 & 2112 \\
\hline
\end{tabular}

Fonte: OuvidorSUS/MS $(2012,2013,2014)$

Em se tratando da participação, a Tabela 2 apresenta um cenário de maior engajamento do cidadão. Das 2.112 manifestações acolhidas, após implantação da Ouvidoria do SUS, 1.266 referem-se à gestão e, dessas, 865 correspondem às reclamações do cidadão quanto aos serviços ofertados. 
Observa-se que o número de reclamações (1.129 manifestações) acolhidas no período é mais que o dobro, por exemplo, das solicitações demandadas (551 manifestações). Isso sugere um avanço na percepção dos cidadãos no que se refere à participação e, possivelmente, apresenta um olhar crítico por parte do cidadão em relação ao que lhe é ofertado.

Em contrapartida, o número registrado de sugestões (114), informações (70) e elogios (174) ainda era muito pequeno em relação ao total de manifestações acolhidas (2.112). No entanto, já aparece numericamente superior ao período anterior, o que demonstra a ampliação do entendimento da participação pelo cidadão. Observa-se que ele entra em contato com a Ouvidoria, não apenas para solicitar algo ou reclamar, mas para dar sugestões para a melhoria do serviço e, em outras vezes, somente para elogiar um serviço ou um servidor.

Nota-se que assuntos como Gestão (1.266 manifestações) e ESF (132 manifestações) estão presentes em ambos os períodos analisados e são assuntos que abordam todas as classificações: denúncia, elogio, informação, reclamação, sugestão e solicitação.

Outro dado interessante a ser observado é a classificação das manifestações por assunto, que traz pela primeira vez: SAMU (36); Assistência Odontológica (17); Cartão SUS (10); Carta SUS e Orientações em saúde (02 manifestações cada); Comunicação (1); e a Ouvidoria (1).

No período pós-implantação da Ouvidoria do SUS no município de Angra dos Reis, que contempla as informações referentes ao triênio de 2016 a 2018, período em que os fluxos e processos de trabalho da Ouvidoria já estão estabelecidos e publicizados, o quantitativo de acessos se manteve (com pequena variação), totalizando 1.871 demandas classificadas (Figura 5).

\section{FIGURA 5 - Quantitativo de manifestações por classificação $(2016,2017,2018)$}

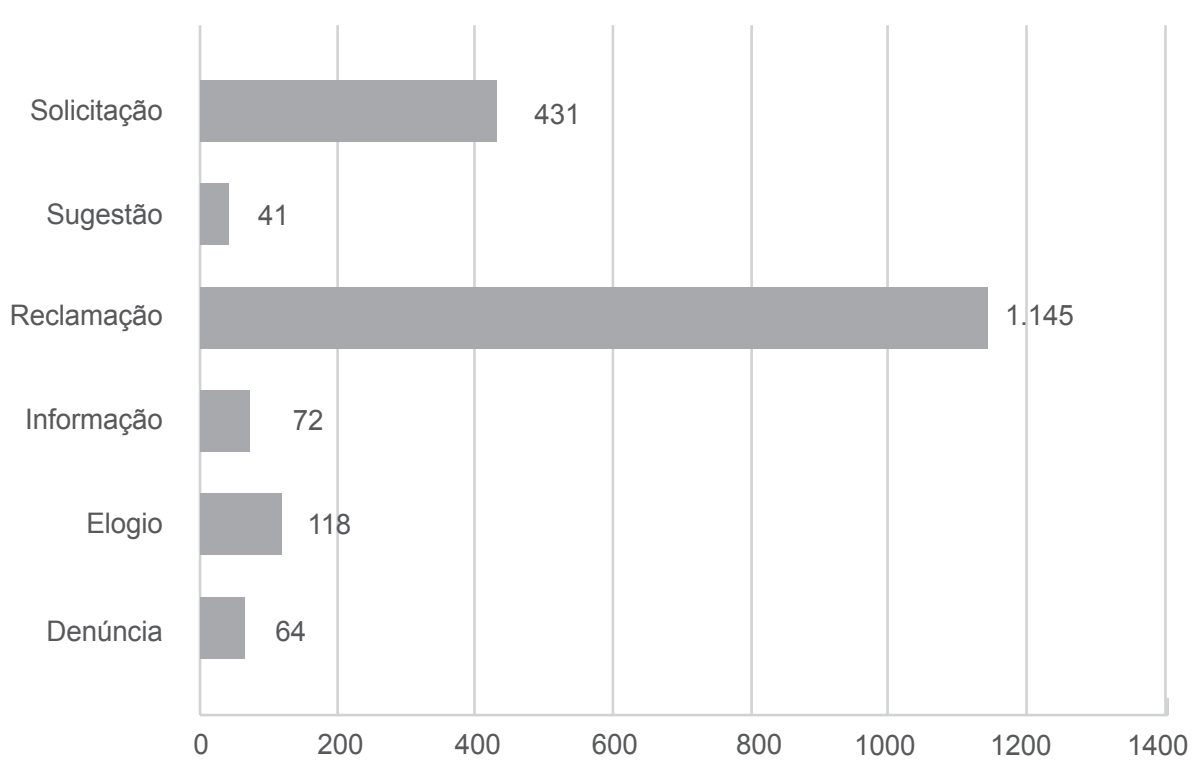

Fonte: Elaborado com base nos dados do OuvidorSUS/MS 
Como apresentado na Figura 6, do total de 1.871 acessos à Ouvidoria, os cidadãos deram preferência ao atendimento por telefone (54\% dos acessos), com 1.015 manifestações, seguido pelo atendimento presencial ( $24 \%$ dos acessos), com 446 manifestações. As manifestações encaminhadas por formulário web, e-mail e carta (22\% dos acessos) contaram 410 demandas no período.

\section{FIGURA 6 - Tipo de atendimento $(2016,2017,2018)$}

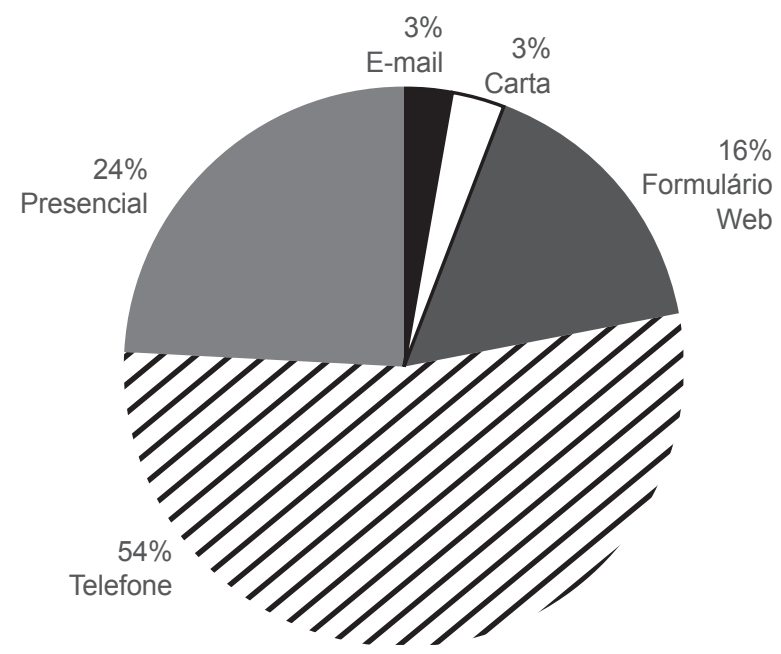

Fonte: Elaborado com base nos dados do OuvidorSUS/MS

Em relação à tipificação por assunto das manifestações apresentadas no período em análise, de janeiro de 2016 a dezembro de 2018, como constatado na Tabela 3, não houve muita variação no quantitativo de acessos à Ouvidoria (1.871).

Assim como nos períodos anteriormente analisados, a Gestão (580), que trata das condições das unidades de saúde, recursos humanos e dificuldade de acesso à Rede de Atenção à Saúde (RAS); as Estratégias de Saúde da Família (480), que trata especificamente do acesso à Atenção Primária à Saúde; e a Assistência à Saúde (420), que trata dos acessos a consultas especializadas e exames, são os assuntos mais demandados pelos cidadãos usuários dos serviços. 


\section{TABELA 3 - Relatório estatístico: Tipificação X Classificação (2016 - 2018)}

\begin{tabular}{|c|c|c|c|c|c|c|c|}
\hline Tipificação por Assunto & Denúncia & Elogio & Informação & Reclamação & Sugestão & Solicitação & Total \\
\hline Alimento & - & - & - & - & 01 & 03 & 04 \\
\hline Assistência à Saúde & 01 & - & 18 & 134 & 3 & 264 & 420 \\
\hline Assistência Farmacêutica & - & - & 05 & 26 & - & 52 & 83 \\
\hline Assistência Odontológica & - & 07 & 01 & 50 & - & 26 & 84 \\
\hline Carta SUS & 01 & - & - & - & - & - & 01 \\
\hline Comunicação & - & - & 01 & 01 & 03 & - & 05 \\
\hline ESF & 03 & 21 & 08 & 427 & 4 & 17 & 480 \\
\hline Financeiro & - & - & 06 & 01 & - & 01 & 08 \\
\hline Gestão & 19 & 87 & 17 & 404 & 30 & 23 & 580 \\
\hline Orientação em Saúde & - & - & 02 & - & - & - & 02 \\
\hline Ouvidoria do SUS & - & 01 & - & - & - & - & 04 \\
\hline $\begin{array}{l}\text { Produtos para Saúde e } \\
\text { Correlatos }\end{array}$ & - & - & 01 & 14 & - & 14 & 29 \\
\hline $\begin{array}{l}\text { Programa Nacional de } \\
\text { Controle do Tabagismo }\end{array}$ & - & - & 01 & - & - & - & 01 \\
\hline SAMU & 03 & 02 & - & 15 & - & - & 20 \\
\hline Transporte & 03 & - & 01 & 47 & - & 12 & 63 \\
\hline Vigilância em Saúde & 08 & - & 10 & 23 & - & 16 & 57 \\
\hline Vigilância Sanitária & 26 & - & 01 & 03 & - & 02 & 32 \\
\hline TOTAL & 64 & 118 & 72 & 1.145 & 41 & 431 & 1.873 \\
\hline
\end{tabular}

Fonte: OuvidorSUS/MS (2016, 2017, 2018)

Em relação ao quantitativo de demandas acolhidas e encaminhadas pela Ouvidoria do SUS, nos três períodos analisados, tem-se a Figura 7.

\section{FIGURA 7 - Quantitativo de manifestações acolhidas (2009 a 2018)}

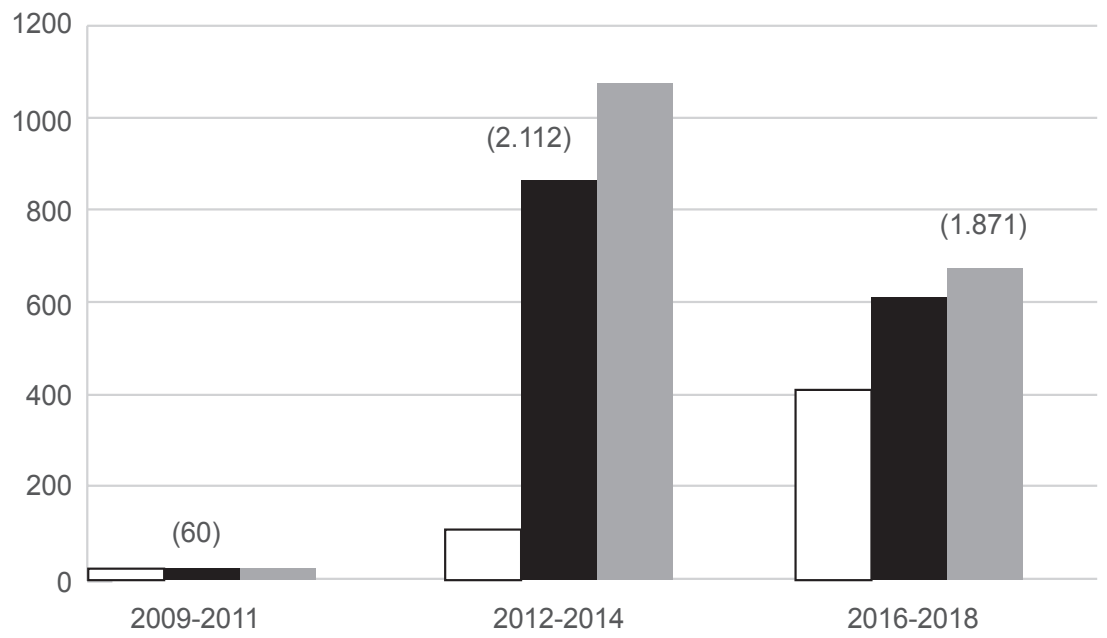

Fonte: Elaborado com base nos dados do OuvidorSUS/MS 
O acesso do cidadão pelo canal da Ouvidoria do SUS sugere que, passado o momento inicial da implantação (onde se supõe que havia uma demanda reprimida), a Ouvidoria se concretizou como canal de participação, pois o quantitativo de demandas continua alto e aponta para esse entendimento, por parte do cidadão, que procura o serviço (Figura 7).

\section{CONCLUSÃO}

Pelo exposto, percebe-se que a Ouvidoria do SUS da SMS de Angra dos Reis é uma ferramenta de participação e de controle social na gestão pública de saúde no contexto da democracia participativa, pela qual o cidadão, usuário do SUS, pode se manifestar e, com isso, contribuir para a melhoria da qualidade da saúde. Constitui ainda um canal democrático de articulação entre o cidadão e a gestão, com vistas a garantir o efetivo acesso ao direito à saúde, orientando o cidadão quanto ao seu direito e apontando aos gestores as possíveis falhas do serviço ofertado.

Observa-se também que as demandas da Ouvidoria reúnem um significativo volume de informações quanto aos serviços ofertados aos cidadãos, que devem ser avaliadas continuamente, permitindo assim a apuração permanente das necessidades e interesses dos cidadãos usuários do SUS. Entretanto, quando se avalia o avanço da participação democrática no município de Angra dos Reis, constata-se que existe um longo caminho a ser percorrido para obter uma gestão que tenha como centro o cidadão e sua participação na definição das políticas de saúde, no acesso às informações, no respeito à sua individualidade e aos seus direitos.

Muito embora se constate que a Ouvidoria tem contribuído para o acesso do cidadão e promoção do diálogo e do envolvimento de gestores na resolução das questões apresentadas pelo cidadão usuário do SUS, e entender que uma Ouvidoria de SMS não tem caráter resolutivo dentre suas atribuições, considera-se que o tempo de respostas às manifestações continua inadequado (até 60 dias), descumprindo, algumas vezes, o prazo previsto pela Lei 13.460/17, que determina prazo de resposta de 20 dias, a contar do encaminhamento da demanda, prorrogável de forma justificada, uma única vez, por igual período.

Das limitações encontradas para realização desse estudo, a falta de relatórios gerencias anteriores ao ano de 2017 por parte da Ouvidoria trouxe dificuldades para que se identificasse qual a visão do serviço para com as demandas dos cidadãos, quais critérios foram usados para o encaminhamento das demandas e o que foi repassado aos cidadãos.

Entende-se que outros estudos serão necessários, no sentido de mostrar a realidade considerando as dimensões gerenciais e de satisfação dos cidadãos usuários do SUS, para que se possa avançar rumo ao SUS com acesso de fato universal.

\section{REFERÊNCIAS}

BORDENAVE, Juan E. D. O que é participação. 3. ed. São Paulo: Brasiliense, 1985. 35 p.

BRASIL. Constituição Federal (1988). Constituição da República Federativa do Brasil. Brasília, DF: Senado, 1988. Disponível em:<http://conselho.saude.gov.br/web_sus20anos/20anossus/legislacao/constituicaofederal.pdf >Acesso em: 24 jan. 2015. 
. Lei n 8080 de 19 de setembro de 1990: Lei Orgânica da Saúde. <http://bvsms.saude.gov.br/bvs/ publicacoes/progestores/leg_sus.pdf> Acesso em: 23 jul. 2019.

. Lei no 13.460 de 27 de junho de 2017: Lei de Defesa do Usuário. <https://www2.camara.leg.br/legin/ fed/lei/2017/lei-13460-26-junho-2017-785098-publicacaooriginal-153203> Acesso em: 23 jul. 2019.

. Ministério da Saúde. Falando de Ouvidoria: experiência e reflexões. Brasília, 2010. Disponível em: <ftp:// balcao.saude.ms.gov.br/horde/ouvidoria/material_implantacao/compendio_ouvidoria_geral_sus.pdf> Acesso em: 24 jan. 2015.

Ministério da Saúde: OuvidorSUS. Brasília, 2009. Disponível em: <http://ouvprod02.saude.gov.br/

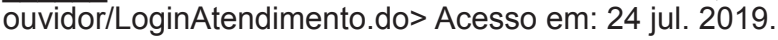

CELLARD, A. A análise documental. In: POUPART, J. et al. A pesquisa qualitativa: enfoques epistemológicos e metodológicos. Petrópolis: Vozes, 2008.

CÔRTES, Soraia V. Conselhos e conferências de saúde: Papel institucional e mudança nas relações entre Estado e sociedade. Seminário Saúde e Democracia: participação política e institucionalidade. CEBES. Río de Janeiro, 2008.

DAHL, Robert. Poliarquia: participação e oposição. São Paulo: Edusp, 2005.

DUARTE, Neucimar de Oliveira. A participação dos enfermeiros de Saúde da Família no controle social em saúde: o caso de Angra dos Reis. Rio de Janeiro: UFRJ / EEAN, 2010.

FORTES, N. M. As Ouvidorias Públicas como espaço de inclusão da cidadania. Belo Horizonte: ABO-MG, 2009.

SOUZA, Luciana de Aguiar Albano et al. Curso de capacitação profissional em Ouvidoria do SUS: programa de educação à distância. Brasília: Editora Universidade de Brasília, 2007.

TEIXEIRA, Juliana Cristina; ARAUJO, Priscila Gomes de; PIMENTEL, Mariana Pereira Chaves. Reflexões sobre uma gestão pública adjetivada como social. Apresentado no VII SEGeT: Simpósio de Excelência em Gestão e Tecnologia, 2010. 